\title{
Relation between Local Structure and Glass Forming Ability of Liquid Alloys
}

\author{
Y. Waseda ${ }^{a}$, H. S. Chen ${ }^{b}$, K. T. Jacob ${ }^{\text {a.c }}$ and H. Shibata ${ }^{a}$ \\ anstitute of Multidisciplinary Research for Advanced Materials (IMRAM), \\ Tohoku University, Sendai 980-8577, Japan. \\ b Bell Laboratories, Lucent Technology, New Jersey 07974, U.S.A. \\ ${ }^{c}$ Department of Materials Engineering, Indian Institute of Science, Bagalore 560012, India.
}

(Received April 20,2007: final form July 31,2007)

\begin{abstract}
An attempt has been made to describe the glass forming ability (GFA) of liquid alloys, using the concepts of the short range order (SRO) and middle range order (MRO) characterizing the liquid structure. A new approach to obtain good GFA of liquid alloys is based on the following four main factors: (1) formation of new SRO and competitive correlation with two or more kinds of SROs for crystallization, (2) stabilization of dense random packing by interaction between different types of SRO, (3) formation of stable cluster (SC) or middle range order (MRO) by harmonious coupling of SROs, and (4) difference between SRO characterizing the liquid structure and the near-neighbor environment in the corresponding equilibrium crystalline phases.

The atomic volume mismatch estimated from the cube of the atomic radius was found to be a close relation with the minimum solute concentration for glass formation. This empirical guideline enables us to provide the optimum solute concentration for good GFA in some ternary alloys.

Model structures, denoted by Bernal type and the Chemical Order type, were again tested in the novel description for the glass structure as a function of solute concentration. We illustrated the related energetics of the completion between crystal embryo and different types of SRO. Recent systematic measurements also provide that thermal diffusivity of alloys in the liquid state may be a good indicator of their GFA.
\end{abstract}

Keywords: Metallic glass: Short-range ordering; Middle-range ordering; Stable cluster: thermal diffusivity

\section{INTRODUCTION}

A large number of attempts to produce metallic glasses have been reported and numerous alloy systems were found to form the glassy phase by direct melt processing techniques such as chill block casting of ribbon and free jet spinning of wire. Since the quenching rate is of the order of $10^{6} \mathrm{~K} / \mathrm{s}$, the glassy samples were usually obtained in the form of ribbon with thickness of $30 \mu \mathrm{m}$ or wire with diameter of 100 $\mu \mathrm{m}$.

The addition of third elements which exhibit different properties, such as atomic size and crystalline symmetry to a binary alloy, is known to enhance drastically the ease of glass formation. One of the reasons for this is considered the lowering of the melting temperature. Then some exceptional systems such as $\mathrm{Au}-\mathrm{Ge}-\mathrm{Si}, \mathrm{Pd}-\mathrm{Cu}-\mathrm{Si}, \mathrm{Pd}-\mathrm{Ni}$-P and $\mathrm{Pt}-\mathrm{Ni}-\mathrm{P}$ were found to be produced as cylindrical rods of 1 to $3 \mathrm{~mm}$ diameter in the glassy state at quenching rate of only $10^{2}$ $\mathrm{K} / \mathrm{s} / 1,2 /$.

Inoue, Zhang and Masumoto $13,4 /$ in 1990 discovered new ternary alloy systems of $\mathrm{Zr}-\mathrm{X}-\mathrm{Y}$ (X= $\mathrm{Al}, \mathrm{Y}=\mathrm{Co}, \mathrm{Ni}, \mathrm{Cu}$ ) which require a quenching rate of the order of $10^{2} \mathrm{~K} / \mathrm{s}$ to produce the glass phase and these alloy systems do not include any non-metallic elements 
such as $\mathrm{P}$ and Si. Peker and Johnson /5/ in 1993 independently reported a highly processable metallic glass made from $\mathrm{Zr}$-Ti-Cu-Ni-Be alloys. These interesting results marked the advent of second generation metallic glasses, so called "bulk metallic glass" $/ 6,7 /$. Inoue and his colleagues have found a large number of alloy systems producing glass phase in the form, not only a cylindrical rods of several millimeters diameter, but also ingots with diameter or thickness larger than several centimeters $/ 8,9 /$, by using the following three empirical guidelines $/ 10-12 /$ :

(1) use of a multi-component system consisting of more than three elements,

(2) significant difference in atomic size (above $12 \%$ ) among the main constituent elements, and

(3) negative enthalpy of mixing among their elements.

The guidelines clearly indicate the importance of the atomic size difference and enthalpy of mixing of the constituent elements for predicting glass forming ability (hereafter referred to as GFA) of liquid alloys. However, three empirical guidelines for designing new metallic glasses do not provide any information about concentration of the elements required for glass formation. Many other empirical guidelines have been proposed for better describing the GFA of liquid alloys 113/. Nevertheless, discovery for new bulk metallic glass still depends, more or less, on trial and error. This strongly requests a comprehensive idea for the GFA of liquid alloys.

The main purpose of this work is to describe the GFA of liquid alloys by using the short range order (hereafter referred to as SRO), characterizing the atomic scale structure of liquid alloys, and the effect of solute elements to the metallic solvent. The basic premise is that good GFA of liquid alloys can be achieved when the liquid phase is stabilized by increasing the local structure ordering in the near-neighbor region as well as by restraining the progress of nucleation and growth of crystallites starting from embryo in the liquid phase. An approach will be made to describe the effects of additive elements on the liquid structure using the following four main factors. (1) formation of new SRO and competitive correlation with two or more kinds of SROs for crystallization, (2) stabilization of dense random packing distribution by interactions between different
SROs, (3) formation of stable cluster (hereafter referred to as SC) or middle range order (hereafter referred to as MRO) by harmonious coupling of SROs, and (4) difference between SRO characterizing the liquid structure and the near-neighbor environment in the corresponding equilibrium crystalline phases which usually precipitate. This factor (4) is well-confirmed by the experiments $/ 14 /$.

\section{A BRIEF BACKGROUND FOR CRYSTALLIZATION AND GENERAL FEATURES OF THE STRUCTURE OF METALLIC LIQUIDS}

Crystallization process from liquid phase can be classified into two categories: "melt growth" arising from super-cooling and "solution growth" due to supersaturation /15/. The present work is concerned with melt growth. Since our target is phase transformation at the solid/liquid interface by decreasing temperature, good GFA of liquid alloys may be obtained when satisfying the conditions of "liquid phase stabilization" induced by increasing the local structure ordering in the extended near-neighbor region as well as "restraint of crystallization in liquid phase" by stopping the progress of nucleation and growth of crystalline phases. It may be noted that many works in the literature clearly indicate that the admixture of metals to form binary alloys or the addition of third elements is required to produce relatively low temperature eutectic reactions and induce good stability as well as the ease of glass formation.

As illustrated in Fig. 1, liquid alloy is in thermodynamic equilibrium with the corresponding vapor phase at high temperature. By decreasing temperature, liquid alloy reaches the triple point (see a point $O$ in Fig. 1 corresponding to $T_{0}$ ). When the temperature is further decreased to $T$ in the absence of suitable crystal nuclei, the liquid phase enters the socalled super-cooled state (see a point $O^{\prime}$ in Fig. 1) given by smooth downward extrapolation of the liquid/gas boundary from the triple point. Such a liquid phase is not the most stable state of aggregation. However, the liquid structure could be effectively frozen to form glass when suitable crystallization nuclei do not exist and 
develop. The degree of super-cooling is presented by $\Delta T$. $=T_{0}-T$. Because of insignificance of variation of melting temperature $T_{\mathrm{m}}$ for metals and alloys with pressure in the vicinity of atmospheric pressure, the approximation of $\Delta T=T_{\mathrm{m}}-T$ is acceptable. Since the progress of nucleation and growth in the region of $\Delta T$ is restrained, the larger the value of $\Delta T$, the ease of glass formation is enhanced.

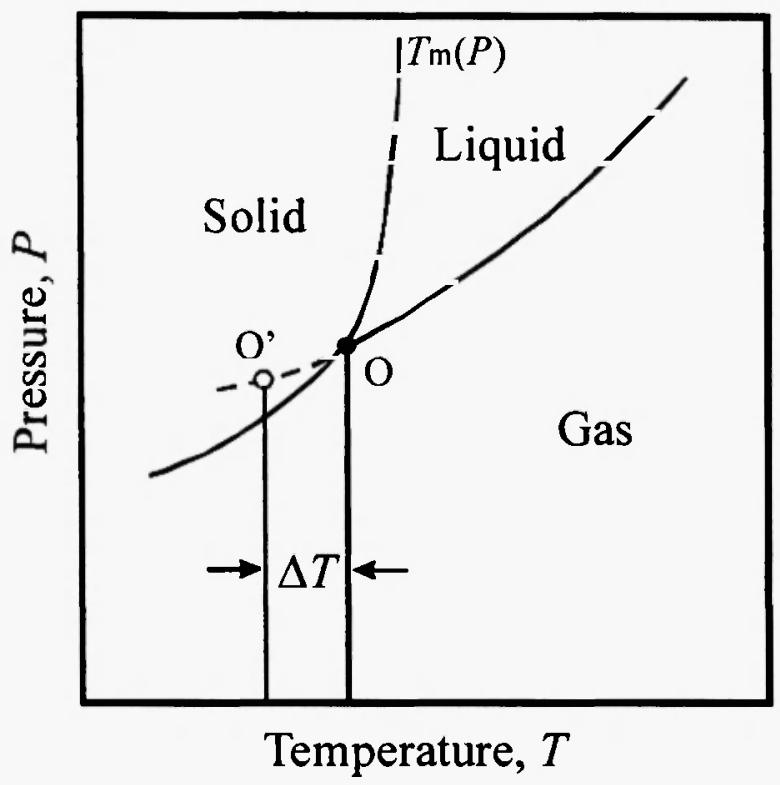

Fig. 1: Schematic phase diagram of a pure metal as a function of pressure and temperature. $7 \mathrm{~m}$ : melting temperature, $O$ : triple point, $O^{\prime}$ : point reached by super-cooling, and $\Delta T$ : the degree of super-cooling.

Very small crystal embryos produced by fluctuations in the liquid are easily dissolved into liquid phase. For the progress of nucleation and growth, the size of crystal embryo should be larger than a critical size, which depends both on the difference in bulk Gibbs energy between the solid and liquid phases and the interface energy. Then, nucleation of crystal embryo from liquid phase is known to be more difficult than its growth $/ 16,17 /$. More details on this subject are given in reference $/ 18$. It should be noted here that good GFA for liquid alloys is considered by introducing factors which restrain the progress of nucleation and growth. One of these factors is experimentally established: the SRO characterizing the liquid structure clearly differs from those found in the corresponding equilibrium crystalline phases that usually precipitate from the melt $/ 14 /$.

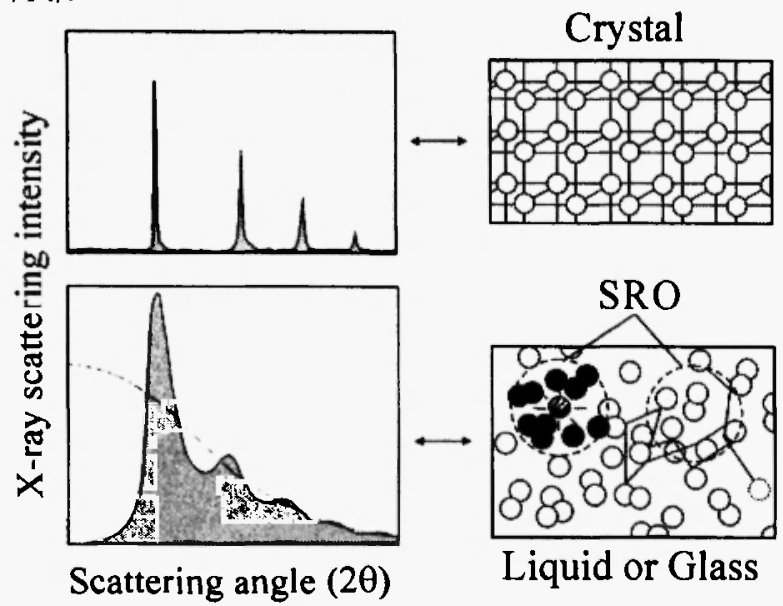

Fig. 2: Schematic diagram for X-ray scattering intensity profiles of crystal and liquid or glass and their atomic distributions. Dotted circles: the examples of SRO found in liquid.

Since the atoms in crystals are known to vibrate around fixed points in the regular three dimensional lattice, several discrete peaks are detected in the X-ray scattering intensity pattern, as shown in Fig. 2(a). All atomic positions in crystals can be described with a few parameters of distances and angles. However, such a simple depiction is not possible in liquids and glasses because of the lack of long-range structural periodicity. On melting, metals and alloys lose the characteristics of their crystal structure and the measured X-ray scattering intensity pattern is represented by a common feature consisting of a relatively sharp first peak followed by a few smaller peaks (see Fig. 2(b)) /19/. Note that absolute intensity is very low but it is observed at all angles and the first peak height of liquid (or glass) is about $10 \%$ when compared with the crystalline case. Since even in non-crystalline systems which lack longrange periodicity, if scattered beams from two atoms coherently interfere with each other, then scattering intensity results depend upon the relative positions of the two atoms. This is the origin for giving $\mathrm{X}$-ray scattering intensity pattern for liquids and glasses. The loss of the long range structural periodicity and the increase in the freedom of atomic distribution on melting contributes to the construction of a rather universal simple atomic distribution which mainly 
depends on the size factor, similar to the hard sphere model $/ 23 /$. This is particularly true at temperatures near the melting point, because the volume change on melting of metallic elements is usually less than a few percent. This is also supported by the isotropic metallic bonding. For these reasons, the short range ordering structure in the near-neighbor region from any atom at origin is clearly found as shown by a dotted circle in Fig. 2 (b) and the average coordination numbers of nearest neighbors is about $10-12$ for most liquid metals 119/. It should be kept in mind that the coordination numbers obtained for liquids clearly differ from the crystalline case, where the fixed coordination numbers can be defined, for example, 8 for the $1^{\text {st }}$ nearest neighbors, 6 for the $2^{\text {nd }}$ and 12 for the $3^{\text {rd }}$ in bcc.

The atomic scale structure of liquids (or glasses) without long-range periodicity can only be quantitatively described in terms of the radial distribution function (frequently referred to as RDF) indicating the average probability of finding another atom in a specified volume from an atom at origin as a function of radial distance. In a liquid system both over time and space, the RDF $=4 \pi r^{2} \rho(r)$ can be defined by considering a spherical shell of radius $r$ with thickness $\mathrm{d} r$ centered on an atom at origin. Here $\rho(r)$ is the socalled radial density function. The RDF gradually approaches the parabolic function of $4 \pi r^{2} \rho_{o}$ at a larger value of $r$, where $\mathrm{p}_{0}$ is the average number density of atoms in a given liquid system, because the positional atomic correlation disappears with increasing distance in liquid. It may be worthy of note that the area under the respective peaks in the RDF provides information about the average coordination numbers of liquid.

Since the bare ions in liquid metals are quite likely to be partially screened by the electron gas suggested by Ziman $/ 20 /$, the effective pair interaction distance in liquid metals is rather close to the atomic diameter. Then, the hard sphere solution of the Percus-Yevick equation moderately reproduces the fundamental profile of measured X-ray scattering intensity of most liquid metals, so long as the packing density is suitably selected, as shown in Fig. $3 / 21 \%$ Here, the packing density is defined by $\eta=\pi \rho_{0} \sigma^{3} / 6$ where $\sigma$ and $p_{0}$ are the hard sphere diameter and the average number density, respectively. The value of packing density of 0.45 is suggested for most liquid metals at temperature close to the meting point /19/. This hard sphere solution of the Percus Yevick equation is also found to work well for binary cases $/ 22 /$. These results imply that the structure of liquid metals can be simply expressed by the random distribution of hard spheres and a topological factor plays an important role in the atomic scale structure of liquid metals.

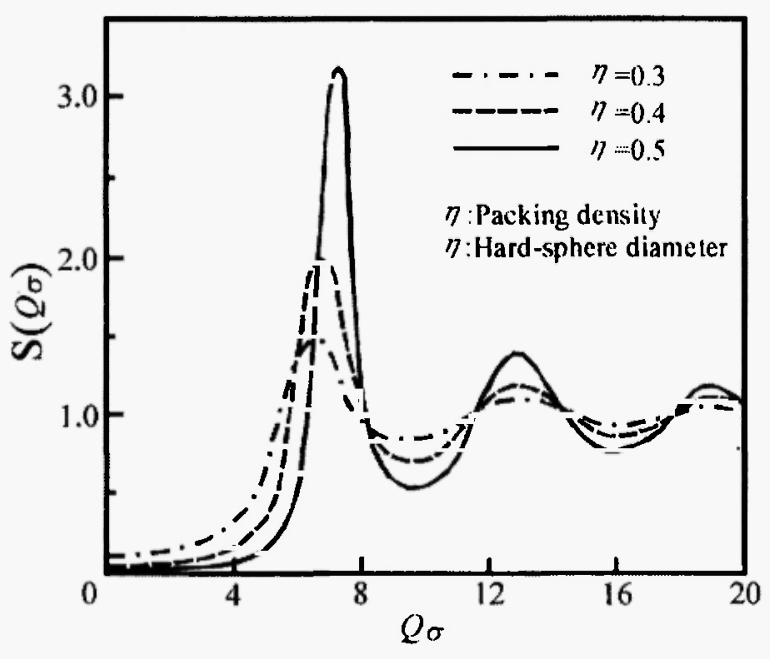

Fig. 3: Structure factors given by the hard sphere solution of the Percus-Yevick equation as a function of packing density $\eta$.

The SRO detected in the random distribution of hard spheres shows average coordination numbers between 10 and 12. However, we should not discuss the SRO found in liquid metals with its direct relevance to the crystalline case, because the ratio $\left(r_{2} / r_{1}\right)$ of the position of the first peak $\left(r_{1}\right)$ to that of the second peak $\left(r_{2}\right)$ is found to be nearly constant at 1.90 for most liquid metals, whereas the ratio $\left(r_{2} / r_{1}\right)$ should have different values depending on the crystal structure. $/ 19 /$.

According to Bernal /23/ and Finny /24/, one can readily find some particular polyhedra, corresponding to SRO, formed by packing equal spheres or cluster consisting of tetrahedral units in a model structure with random distribution for liquid. Such topological SRO (frequently referred to as TSRO) also frequently appears in the structure of ultra fine particles. Note that the tetrahedron and the octahedron are known to be the main components of crystalline structures classified into fcc or hcp. Three topological SROs are illustrated in Fig. 4 using the results of Polk /25/. Triangular prisms capped with three half-octahedra of Fig. 4(a), 
Archimedian anti-prisms capped with two halfoctahedra of Fig.4(b) and tetragonal dodecahedron of Fig.4(c) are not detected in crystal structure of pure metals. However, these polyhedra are known to have a close relation with the local atomic distributions frequently found in some binary compounds such as $\mathrm{Fe}_{3} \mathrm{C}$ and $\mathrm{Pd}_{3} \mathrm{Si}$. Some non-crystallographic unit structures such as 13 atom-icosahedra and 55 atomMackay icosahedral clusters (see Fig.4 (d) and (e)) have also been employed for explaining the characteristic structure of liquid and glass $126,27 \%$. This strongly suggests that some particular local orderings as well as usual SRO are quite likely to exist in liquid and glassy alloys.

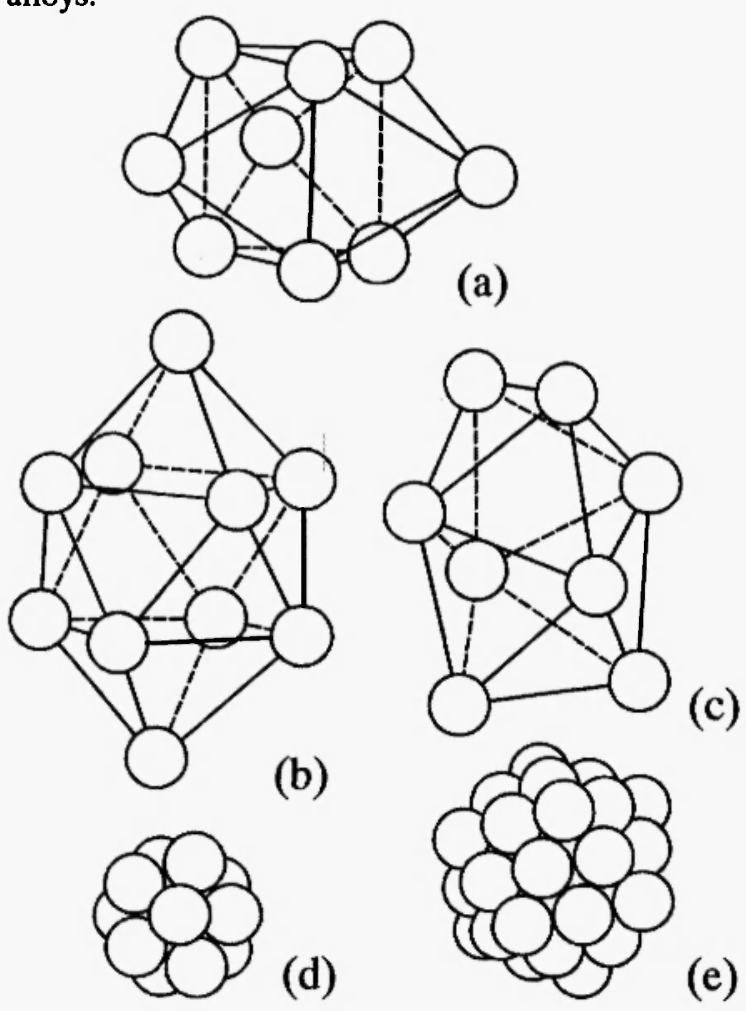

Fig. 4: Three polyhedra formed by packing equal spheres found in a model structure for liquid. (a) triangular prism capped with three halfoctahedra, (b) archimedian anti-prisms capped with two half-octahedra and (c) tetragonal dodecahedron $125 \%$ (d)13 atom-icosahedral cluster and (e)55 atom-Mackay icosahedral cluster for describing the non-crystalline structure 126,27\%. Note: The size of equal spheres of (a), (b) and (c) differs from the (d) and (e) cases.

\section{SOME SELECTED FEATURES OF THE STRUCTURE OF LIQUID ALLOYS WITH GOOD GFA}

A large number of $\mathrm{X}$-ray diffraction studies have been available on the structure of various metallic glasses in the variety of states. On the other hand, structural information for liquid alloys showing good GFA is still very limited to only a small number of compositions. This is mainly because of experimental difficulties arising from chemical reactivity of liquid sample with container materials at higher temperatures. Some characteristic structural features are described, here, using three results for $\mathrm{Pd}_{40} \mathrm{Ni}_{10} \mathrm{Cu}_{30} \mathrm{P}_{20}$ liquid alloy, $\mathrm{Fe}_{70}-\mathrm{Y}_{10}-\mathrm{B}_{20}$ glassy alloys $(\mathrm{Y}=\mathrm{Cr}, \mathrm{W}, \mathrm{Nb}, \mathrm{Zr}$ and $\mathrm{Hf})$ and $\mathrm{Zr}_{65} \mathrm{Al}_{7.5} \mathrm{Ni}_{10} \mathrm{Cu}_{17,5}$ glassy alloy.

Solid lines in Fig. 5(a) show the RDFs of $\mathrm{Pd}_{40} \mathrm{Ni}_{10} \mathrm{Cu}_{30} \mathrm{P}_{20}$ liquid alloy together with those of $\mathrm{Pd}_{40} \mathrm{Ni}_{40} \mathrm{P}_{20}$, as a reference. Figure 5(b) gives the RDFs of these alloys in the glassy state for comparison /28/. Note that $\mathrm{Pd}_{40} \mathrm{Ni}_{10} \mathrm{Cu}_{30} \mathrm{P}_{20}$ alloy is known to produce a glass ingot as large as $72 \mathrm{~mm}$ in diameter $/ 8 /$.

Since the $\mathrm{Pd}_{40} \mathrm{Ni}_{10} \mathrm{Cu}_{30} \mathrm{P}_{20}$ alloy contains four elements, measured structural data contains ten possible atomic pairs; $\mathrm{Pd}-\mathrm{Pd}, \mathrm{Pd}-\mathrm{Ni}, \mathrm{Pd}-\mathrm{Cu}, \mathrm{Pd}-\mathrm{P}, \mathrm{Ni}-\mathrm{Ni}, \mathrm{Ni}-\mathrm{Cu}$, $\mathrm{Ni}-\mathrm{P}, \mathrm{Cu}-\mathrm{Cu}, \mathrm{Cu}-\mathrm{P}$ and $\mathrm{P}-\mathrm{P}$. The contribution from atomic pairs of $\mathrm{Ni}-\mathrm{Ni}, \mathrm{Ni}-\mathrm{P}, \mathrm{Cu}-\mathrm{P}$ and $\mathrm{P}-\mathrm{P}$ can be ignored in the interpretation of the RDFs because the atomic fraction of $\mathrm{Ni}$ is much less than the other three elements ( $\mathrm{Pd}, \mathrm{Cu}$ and $\mathrm{P}$ ) and the scattering factor of $\mathrm{P}$ is considerably less than metallic elements $(\mathrm{Pd}, \mathrm{Ni}$ and $\mathrm{Cu}$ ). Nevertheless, the remaining six partial structures still overlap in the ordinary RDF. In order to overcome such inconvenience, the anomalous $\mathrm{X}$-ray scattering (AXS) method was used, because the environmental RDF around $\mathrm{Cu}$ obtained by the AXS method contains information of only four partials of $\mathrm{Cu}-\mathrm{Pd}, \mathrm{Cu}-\mathrm{Cu}, \mathrm{Cu}-$ $\mathrm{Ni}$, and $\mathrm{Cu}-\mathrm{P}$. Similarly, the environmental RDF around $\mathrm{Ni}$ consists of four partials of $\mathrm{Ni}-\mathrm{Ni}, \mathrm{Ni}-\mathrm{Pd}, \mathrm{Ni}-\mathrm{Cu}$ and $\mathrm{Ni}-\mathrm{P}$. It should also be mentioned that the vertical scale in the environmental RDF differs from the average RDF case due to the difference in weighting factors.

There are two common features in Fig. 5 for $\mathrm{Pd}_{40} \mathrm{Ni}_{10} \mathrm{Cu}_{30} \mathrm{P}_{20}$ alloy: (1) general structural profiles found in the glassy state appear to be the same as that of the liquid case, although a shoulder or the separation of 
the second peak becomes obscure after melting, and (2) a small hump between the first and the second peak in the environmental RDF for $\mathrm{Cu}$ are clearly detected at $r$ $=0.36 \mathrm{~nm}$ (see arrow in Fig.5) in both liquid and glassy

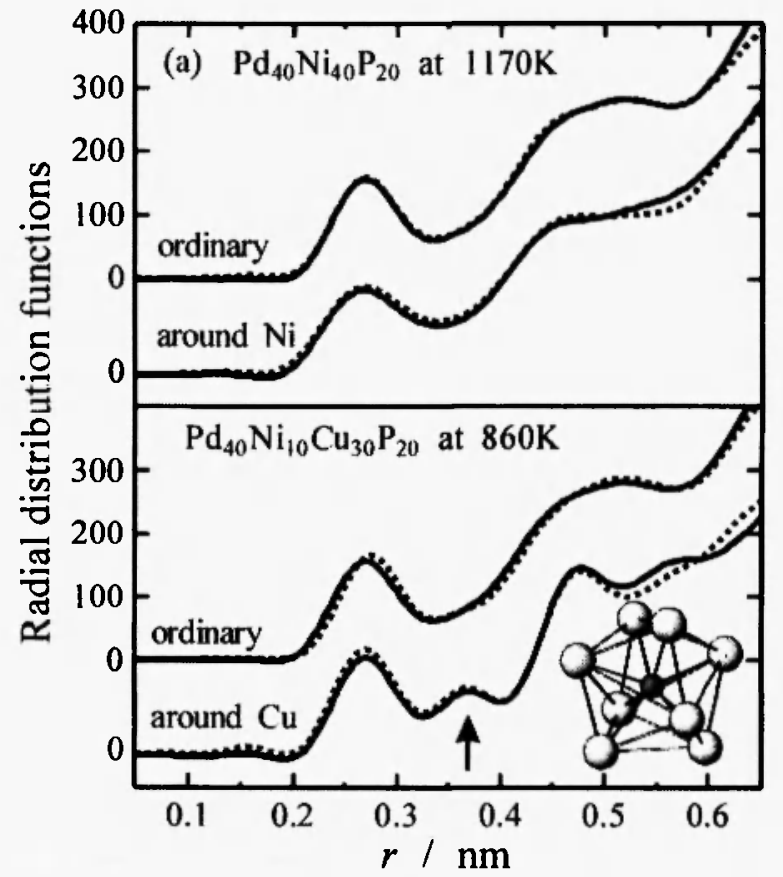

states. Such a small hump is not detected in the environmental RDF for $\mathrm{Ni}$, as well as the average $\mathrm{RDF}$, in this particular quarternary alloy.

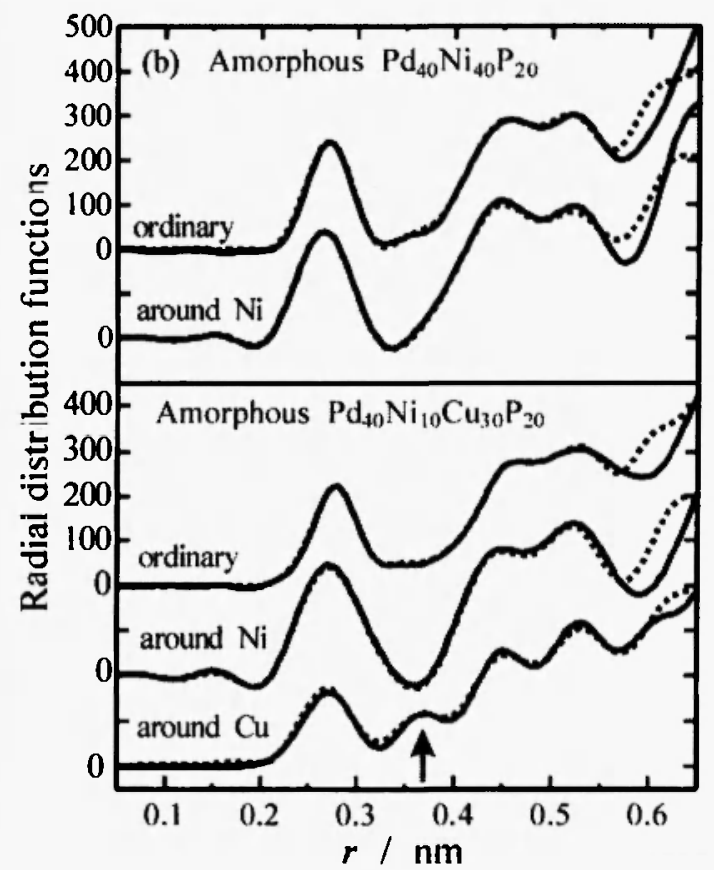

Fig. 5: Average RDF and environmental RDFs for $\mathrm{Cu}$ and $\mathrm{Ni}$ of the $\mathrm{Pd}_{40} \mathrm{Ni}_{10} \mathrm{Cu}_{30} \mathrm{P}_{20}$ alloy in the liquid (a) and glassy (b) states. Dotted lines: the calculated RDFs using the non-linear least square fitting method to reproduce the experimental intensity data coupled with a model (see insert) $/ 28$ /.

The non-linear least square fitting calculation is frequently used for refining the local structure in noncrystalline systems, so as to reproduce the average and environmental structural functions simultaneously /29/ by coupling with a model structure as input. The dotted lines in Fig. 5 are provided by such model calculation, in which we use a tetragonal dodecahedron formed by eight $\mathrm{Pd}$ atoms around $\mathrm{Cu}$ atom. Equal probability for Pd atom occupying vertices was assumed in these polyhedra (see insert of Fig. 5). In this model structure, the distance of two Pd atoms is found close to $0.37 \mathrm{~nm}$. Good agreement between experiment and calculation is obtained as easily seen in Fig. 5, the Pd tetragonal dodecahedral unit around $\mathrm{Cu}$ atom is quite realistic as a local ordering for the $\mathrm{Pd}_{40} \mathrm{Ni}_{10} \mathrm{Cu}_{30} \mathrm{P}_{20}$ alloy in both liquid and glassy states.

$\mathrm{X}$-ray diffraction study for $\mathrm{Fe}_{70}-\mathrm{Y}_{10}-\mathrm{B}_{20}$ glassy alloys $(\mathrm{Y}=\mathrm{Cr}, \mathrm{W}, \mathrm{Nb}, \mathrm{Zr}$ and $\mathrm{Hf})$ has been systematically done with respect to the relation between structure and thermal stability $/ 30 /$. Thermal stability is presented by the temperature span $\left(\Delta T_{\mathrm{X}}\right)$ which is the difference between the crystallization and glass transition temperatures. It is found in decreasing order $89 \mathrm{~K}$ for $\mathrm{Hf}>87 \mathrm{~K}$ for $\mathrm{Zr}>53 \mathrm{~K}$ for $\mathrm{Nb}>41 \mathrm{~K}$ for $\mathrm{W}$ $>0 \mathrm{~K}$ for $\mathrm{Cr}$. The local ordering structures of $\mathrm{Fe}_{70^{-}}-\mathrm{Y}_{10^{-}}$ $B_{20}$ glassy alloys show the following three common features: (1) The local structural unit is a trigonal prism which consists of one $\mathrm{B}$ at the center and six $\mathrm{Fe}$ at the vertices and this is independent of the third element of Y. (2) Most of the trigonal prisms in these alloy glasses are connected by sharing the edge as illustrated in Fig. 6 and the local structural unit varies to a slightly distorted trigonal prism. This is attributed to the replacement of $\mathrm{Fe}$ at the vertices by larger atomic size of $\mathrm{Y}$-element. The larger the distortion of the prism, the more thermally stable the glass structure becomes. (3) The 
trigonal prisms in the less-stable $\mathrm{Fe}_{70}-\mathrm{Cr}_{10}-\mathrm{B}_{20}$ glassy alloy are found to be connected by both edge- and vertex-sharing. It may be safely said that the formation of particular local ordering, leading to SC or MRO by harmonious coupling between more than two kinds of SROs in these ternary glassy alloys in the liquid state.

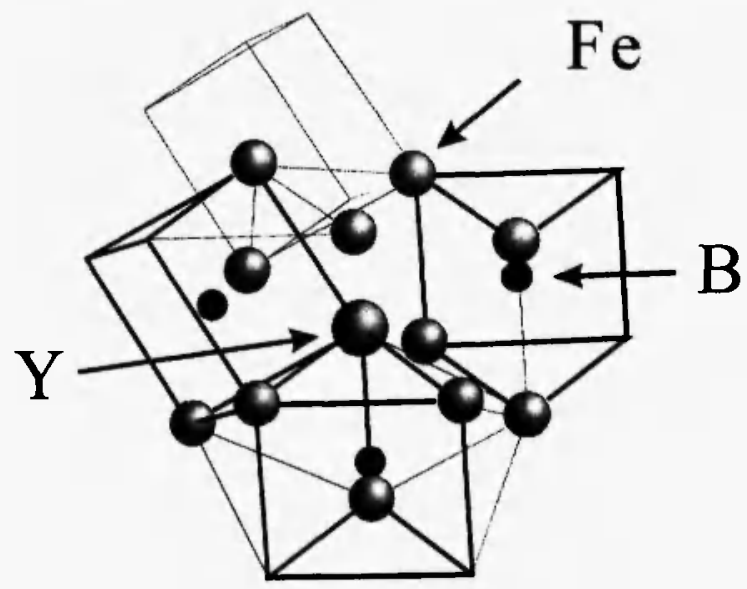

Fig. 6: Local orderings in near neighbor region consisting of trigonal prisms including $M$ proposed for the $\mathrm{Fe}_{70}-\mathrm{Y}_{10}-\mathrm{B}_{20}(\mathrm{Y}=\mathrm{Hf}, \mathrm{Zr}, \mathrm{Nb}$, $\mathrm{W}$ and $\mathrm{Cr}$ ) glassy alloys $/ 30 /$.

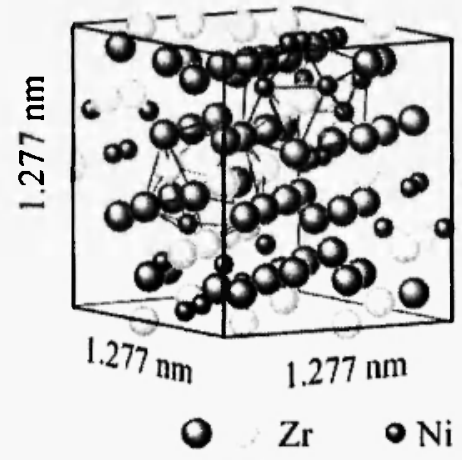

(a)

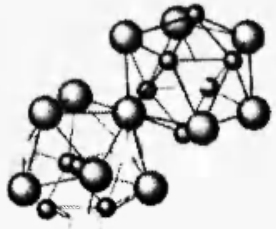

(b)
Fig. 7: Local orderings in near neighbor region consisting of icoshedral cluster (the $\mathrm{Zr}_{2} \mathrm{Ni}$ case) proposed for the $\mathrm{Zr}_{65} \mathrm{Al}_{75} \mathrm{Ni}_{10} \mathrm{Cu}_{17.5}$ glassy alloy $/ 32 /$.

Such particular local ordering has also been suggested for other metallic glasses. It is also mentioned that such local ordering can be detected in the precipitated meta-stable phases with a relatively large lattice parameter when alloy glasses are annealed at low temperature; for example, $\mathrm{Pd}_{15} \mathrm{P}_{2}(a=0.711 \mathrm{~nm}, c=1.709$ $\mathrm{nm} / 31 /)$ and $\mathrm{Zr}_{2} \mathrm{Ni}(a=1.227 \mathrm{~nm} / 32 /)$. In the $\mathrm{Zr}_{2} \mathrm{Ni}$ case, the icosahedral cluster consisting of $\mathrm{Zr}$ and $\mathrm{Ni}$ is suggested as illustrated in Fig. 7 using the result of the $\mathrm{Zr}_{63} \mathrm{Al}_{7,5} \mathrm{Ni}_{10} \mathrm{Cu}_{17.5}$ glassy alloy, as an example $/ 26,32$.

All these results clearly suggest the formation of particular local ordering structures leading to SC or MRO by coupling in harmony with more than two kinds of SROs in multi-component liquid alloys.

\section{NEW APPROACH FOR GLASS FORMING ABILITY OF LIQUID ALLOYS}

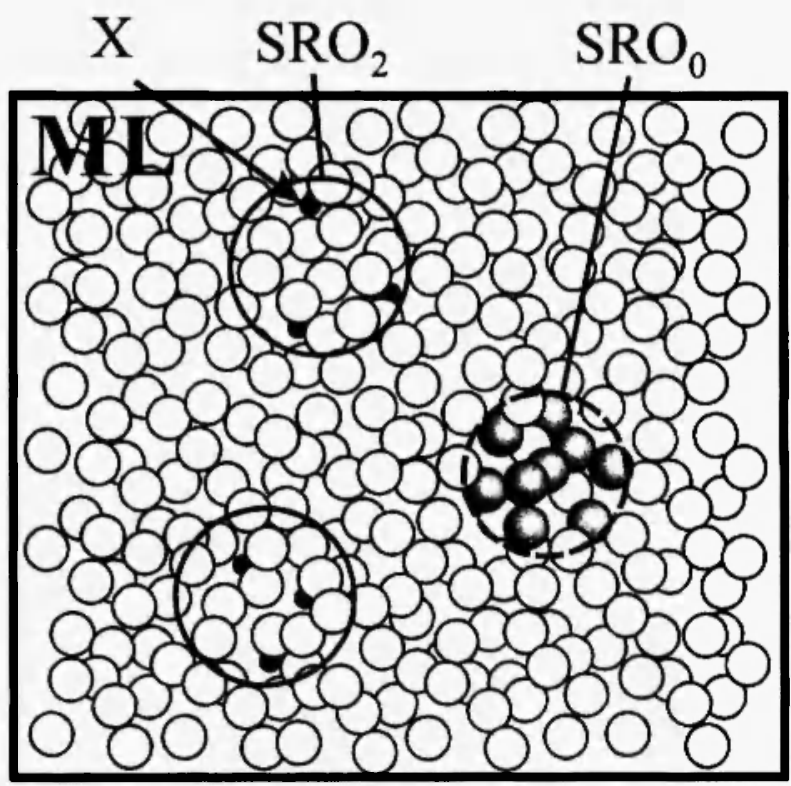

Fig. 8: Schematic diagram for liquid alloys (case-I) when a small amount of second element $(\mathrm{X})$ is added to a metallic solvent (M). Image of coexistence of $\mathrm{SRO}_{0}$ and $\mathrm{SRO}_{2}$. ML: mean liquid structure of solvent $M$.

The structure of host metallic liquid (solvent) can be described by the dense random packing (referred to as DRP) of $M$. In such solvent liquid structure, one can easily find SRO (referred to as $\mathrm{SRO}_{0}$ ) formed by about 10-12 atoms at a distance of the nearest neighbors from an atom at origin. The formation and dissolution of $\mathrm{SRO}_{0}$ itself is repeated because of high atomic vibration in liquid, but it can be defined in the spherical shell at the nearest neighbor distance when averaging over time 
and space (see Fig. 8). It should also be mentioned that the SRO characterizing the liquid structure differs from those in the corresponding equilibrium crystalline phases that usually precipitate in many alloy cases showing good GFA /14/. These pictures are a starting point for further consideration.

\subsection{Effect by adding the second element $(X)$ into host metallic liquid (M)}

Let us consider the case of adding a second element of $\mathrm{X}$ whose atomic size is considerably smaller than that of the metallic solvent of $\mathrm{M}$. This category includes the addition of $\mathrm{B}$ into $\mathrm{Fe}$ or $\mathrm{Si}$ into Pd. In this case, the basic structural profile described by DRP of host metallic element of $\mathrm{M}$ (for example, $\mathrm{Fe}$ or $\mathrm{Pd}$ ) is unchanged and the additive element ( $\mathrm{B}$ or $\mathrm{Si}$ ) is considered to occupy the relatively large vacant space present in the DRP structure. This corresponds to a picture that a certain amount of "defects" in DRP are filled by $X$ in order to be surrounded by $M$ atoms leading to the formation of new SRO (referred to as $\mathrm{SRO}_{2}$ ). This also produces a distorted environmental atomic configuration around $X$ because of the atomic size difference. These variations are quite likely to contribute to stabilizing the liquid phase disorder in the atomic distribution. Nucleation of crystal embryo in the liquid phase and its growth process may also be restrained by competitive correlation of $\mathrm{SRO}_{0}$ with $\mathrm{SRO}_{2}$ in the M-X liquid alloy. This may be true in comparison with the liquid phase consisting of $\mathrm{M}$ alone, because $\mathrm{X}$ is usually selected for strong atomic interactions with $M$ (negative enthalpy of mixing) for easy glass formation. For convenience, Fig. 8 provides the schematic diagram for liquid alloys when a small amount of the second element $(\mathrm{X})$ is added to metallic solvent (M) and $\mathrm{SRO}_{0}$ co-exists with $\mathrm{SRO}_{2}$ in the $\mathrm{M}-\mathrm{X}$ liquid alloy. Since the number of $\mathrm{SRO}_{2}$ depend on the concentration of $\mathrm{X}$, glass formation is not attained in dilute alloys. In other words, the minimum solute concentration $\left(C_{X}^{m}\right)$ necessary to form glass should provide sufficient stabilization of the liquid phase as well as restrain nucleation and growth of crystallites due to some competitive correlation with more than two kinds of SROs in the liquid alloy. This subject will be discussed in the following section.

Let us consider, next, a metallic binary alloy formed for example by addition of $\mathrm{Ni}$ into $\mathrm{Hf}$ or $\mathrm{Cu}$ into $\mathrm{Zr}$. In this case, the basic structural profile is again described by DRP of host metallic element of $M$ with $X$. The local ordering at a distance of the nearest neighbors slightly changes from DRP of $M$ alone, because of the replacement of $\mathrm{X}$ for $\mathrm{M}$ at random. This situation also leads to the formation of new SRO (referred to as $\mathrm{SRO}_{2}$ ). The liquid phase disorder in the atomic distribution associated with this alloying substitution improves the stability and the ease of glass formation. Since $\mathrm{X}$ is usually selected to show the strong atomic interactions with $\mathrm{M}$ for easy glass formation, nucleation and growth of crystallites may also be restrained by competitive correlation of $\mathrm{SRO}_{0}$ with $\mathrm{SRO}_{2}$ in the $\mathrm{M}-\mathrm{X}$ liquid alloy.

\subsection{Effect by adding the third element $(Y)$ into metallic liquid (M) containing $X$}

When the third element $(\mathrm{Y})$ is added into the binary M-X liquid alloy, the_formation of $\mathrm{SRO}_{3}$ arising from the interaction of $M$ and $Y$ is expected, so that the ternary liquid structure is possibly characterized by the co-existence of $\mathrm{SRO}_{0}, \mathrm{SRO}_{2}$ and $\mathrm{SRO}_{3}$. This may further enhance the ease of glass formation, in comparison to the two cases of liquid with $\mathrm{SRO}_{0}$ alone or liquid with $\mathrm{SRO}_{0}$ and $\mathrm{SRO}_{2}$. However, the present authors maintain the view that a more important role of the third element is to provide a linkage with more than two kinds of SROs as shown in Figs. 6 and 7. Namely, there is every probability of the formation of stable SRO which may be designated as SC or MRO, here referred to as $\mathrm{SRO}_{3}$, by harmonious coupling with more than two kinds of SROs around the third element (Y). It may be safely said that the effect of the third element $(Y)$ on the liquid structure of $\mathrm{M}$ containing $\mathrm{X}$ can be explained by the strong interaction with more than two kinds of SROs which is comparable to the formation of new stable SRO. The liquid phase disorder in the atomic distribution associated with the formation of new stable $\mathrm{SRO}\left(\mathrm{SRO}_{3}=\mathrm{SC}\right.$ or $\left.\mathrm{MRO}\right)$ considerably improves both the stability and the ease of glass formation. Nucleation and growth process may also be restrained by increasing the energy requirement for atomic re-distribution involving the stable $\mathrm{SRO}\left(\mathrm{SRO}_{3}\right)$. This is also consistent 
with the fact that both $\mathrm{X}$ and $\mathrm{Y}$ are usually selected to show the strong atomic interactions with $M$ for easy glass forming alloy combination. Figure 9 provides the schematic diagram for liquid alloys when added a small amount of the third element $(Y)$ into metallic solvent (M) containing $\mathrm{X}$. This corresponds to the image of formation of the stable $\mathrm{SRO}\left(\mathrm{SRO}_{3}=\mathrm{SC}\right.$ or MRO) by harmonious coupling with more than two kinds of SROs.

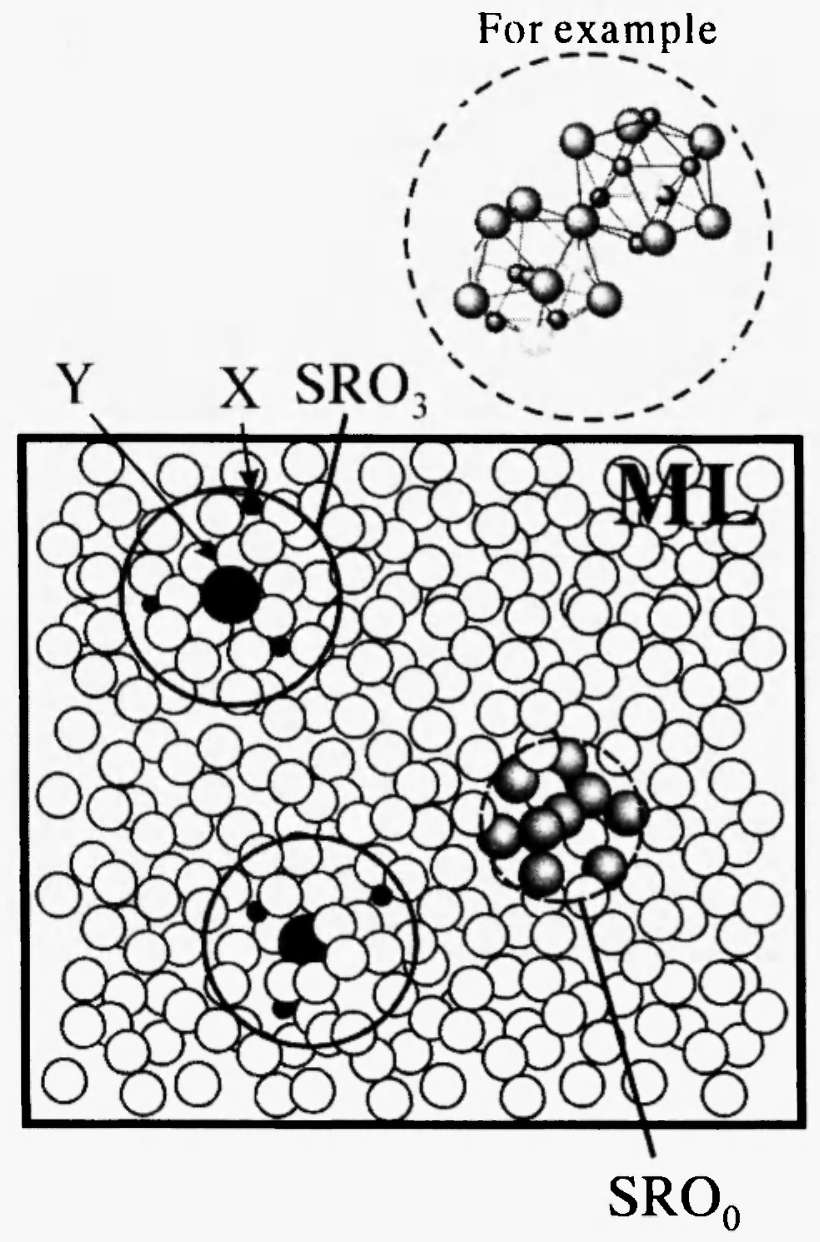

Fig. 9: Schematic diagram for liquid alloys (case-II) when a small amount of the third element $(Y)$ is added to a metallic solvent (M) containing $X$. Image of formation of stable cluster (SC) or $\left(\mathrm{MRO}, \mathrm{SRO}_{3}\right)$ by harmonious coupling with more than two kinds of SROs. ML: mean liquid structure of solvent $M$.

The topological factor such as the atomic size difference primarily contributes to the GFA of liquid alloys, so that it is quite interesting to note that the empirical guidelines found for binary liquid alloys $/ 33$ / give an optimum criterion for the GFA of ternary liquid alloys. The essential points are as follows. The addition of the solute elements $\mathrm{X}$ or $\mathrm{Y}$ could stabilize the DRP structure of the host metallic element by allowing an appropriate distorted environmental atomic distribution with SRO and such a structural feature is primarily induced by the atomic size difference of the constituent elements. With respect to such atomic size difference effects and the solute concentration on the GFA of binary liquid alloys, the following equations using the cube of the atomic radius of the constituent elements have been proposed $/ 33 /$.

$$
\begin{aligned}
& \lambda=\left|\Delta V_{\mathrm{MX}} / V_{\mathrm{M}}\right| \cdot C_{\mathrm{X}}^{\mathrm{m}} \\
& \Delta V_{\mathrm{MX}} / V_{\mathrm{M}}=\left(r_{\mathrm{X}}{ }^{3}\right)-\left(r_{\mathrm{M}}{ }^{3}\right) /\left(r_{\mathrm{M}}{ }^{3}\right)=\left(r_{\mathrm{X}} / r_{\mathrm{M}}\right)^{3}-1
\end{aligned}
$$

where $C_{\mathrm{X}}^{\mathrm{m}}$ is the minimum concentration of $\mathrm{X}$ necessary to obtain a glass phase by rapid quenching from the melt. The values of $r_{\mathrm{M}}$ and $r_{\mathrm{X}}$ are the atomic radius of the host metal of $M$ and the second element $X$, respectively. Equation (2) represents the volume mismatch and the absolute value of $\left|\Delta V_{\mathrm{MX}} / V_{\mathrm{M}}\right|$ may be a suitable indicator of the atomic size difference of the constituent elements. Although the cube of the atomic radius has the dimensions of atomic volume, it is not the same as atomic volume estimated from density and atomic mass. The following results are obtained from the estimation of $\left|\Delta V_{M X} / V_{M}\right|$ and the atomic size difference factor $\lambda$ for 80 binary systems $/ 34 /$.

(1) A smaller value of $C_{\mathrm{X}}^{\mathrm{m}}$ is found in alloys with larger value of the volume mismatch of $\Delta V_{\mathrm{MX}} / V_{\mathrm{M}}$. The converse is also true.

(2) The value of $\lambda$ appears to be almost a constant. The average value of $\lambda$ is 0.101 with a standard deviation of $\sigma=0.021$ for 74 systems, excluding six exceptions 133\%.

The second observation is considered to be quite worthy of note. The effect of the second element on the GFA depends not only on atomic size difference but also on concentration. This simple relation of $\lambda=0.10$ obtained from many experimental studies clearly covers 
both metal-metalloid alloys and metal-metal alloys and this relation holds well when the glass formation is reported at both ends of a binary alloy $133,34 /$.

The minimum solute concentration $\left(C_{Y}^{n_{1}}\right)$ of the third element $(Y)$ to obtain a glassy phase may be described in the following equations, along the line similar to the binary case.

$$
\begin{aligned}
& \lambda^{\prime}=\left|\Delta V_{\mathrm{MX}} / V_{\mathrm{M}}\right| \cdot C_{\mathrm{X}}+\left|\Delta V_{\mathrm{MY}} / V_{\mathrm{M}}\right| \cdot C_{\mathrm{Y}}^{\mathrm{m}} \\
& \Delta V_{\mathrm{MY}} / V_{\mathrm{M}}=\left(r_{\mathrm{Y}}{ }^{3}\right)-\left(r_{\mathrm{M}}{ }^{3}\right) /\left(r_{\mathrm{M}}{ }^{3}\right)=\left(r_{\mathrm{Y}, r_{\mathrm{M}}}\right)^{3}-1
\end{aligned}
$$

where $C_{\mathrm{Y}}^{\mathrm{m}}$ is the minimum concentration of $\mathrm{Y}$ necessary to obtain a glass phase by rapid quenching from liquid alloys at constant value of $C_{\mathrm{X}}$ for the second element $\mathrm{X}$. Atomic radius of the third element $\mathrm{Y}$ is denoted by $r_{Y}$. The systematic experimental results on the GFA of ternary alloys are very limited. Nevertheless, the rather surprisingly interesting results have been obtained. The results for 27 cases are listed in Table $1 / 34,35 /$. Here, the values of $\lambda^{\prime}$ were estimated using Eq. (3) from available data on the GFA of Fe-Y$B, F e-Y-P$ and $C o-Y-B$ ternary liquid alloys, where $Y$ is either a metal or metalloid element such as $\mathrm{Nb}, \mathrm{Mo}, \mathrm{Si}$ and $C$. Note that these experimental results provide the minimum concentration of boron or phosphorus (the second element) at constant value of $C_{Y}$ for the third element $Y$. The empirical relation of $\lambda^{\prime}=0.10$ is found to hold well for the ternary alloys. The agreement between experiment and calculation is fairly good considering the phenomenology. This means that the topological factor primarily contributes to the GFA of liquid alloys so as to stabilize the DRP structure with some defects due to the atomic size difference in harmony among three elements. However, it should be kept in mind that Eq.(3) does not provide any direct relation to the effect of the third element $(Y)$ on the liquid structure of $M$ containing $X$ leading to the formation of new stable SRO. For this purpose, another sensitive parameter for explaining the effect of 1 or $2 \%$ addition on the GFA of liquid alloys is strongly required. Possible candidates are increasing of the temperature coefficient of viscosity near the glass transition temperature $/ 36 /$ or lowering of the melting temperature $/ 37 /$ as a function of concentration of $Y$.

Table 1

Minimum concentration of boron or phosphorus (the second element) at constant value of $C_{Y}$ for the third element(Y)

\begin{tabular}{|c|c|c|c|c|c|c|c|c|}
\hline \multirow[b]{2}{*}{$\mathrm{Y}$} & \multicolumn{2}{|c|}{$\mathrm{Fe}-\mathrm{Y}_{10}-\mathrm{B}_{X}$} & \multirow[b]{2}{*}{$Y$} & \multicolumn{2}{|c|}{$\mathrm{Fe}-\mathrm{Y}_{10}-\mathrm{P}_{X}$} & \multirow[b]{2}{*}{$Y$} & \multicolumn{2}{|c|}{$\mathrm{Fe}-\mathrm{Y}_{10}-\mathrm{B}_{X}$} \\
\hline & $C_{\mathrm{B}}^{\min }$ & $\lambda^{\prime}$ & & $C_{\mathrm{P}}^{\min }$ & $\lambda^{\prime}$ & & $C_{\mathrm{B}}^{\text {min }}$ & $\lambda^{\prime}$ \\
\hline $\mathrm{Nb}$ & 6 & 0.094 & $\mathrm{Nb}$ & 11 & 0.106 & $\mathrm{Nb}$ & 4 & 0.079 \\
\hline Mo & 9 & 0.098 & Mo & 13 & 0.096 & Mo & 9 & 0.098 \\
\hline $\mathrm{V}$ & 11 & 0.100 & $\mathrm{~V}$ & 14 & 0.088 & $\mathrm{~V}$ & 13 & 0.115 \\
\hline $\mathrm{Cr}$ & 11 & 0.090 & $\mathrm{Cr}$ & 14 & 0.078 & $\mathrm{Cr}$ & 13 & 0.105 \\
\hline $\mathrm{Ni}$ & 13 & 0.101 & $\mathrm{Ni}$ & 15 & 0.078 & $\mathrm{Ti}$ & 7 & 0.103 \\
\hline Mn & 13 & 0.111 & Mn & 11 & 0.070 & $\mathrm{Ta}$ & 5 & 0.096 \\
\hline$P$ & 2 & 0.068 & B & 6 & 0.109 & $\mathrm{Mn}$ & 13 & 0.110 \\
\hline $\mathrm{C}$ & 6 & 0.125 & $\mathrm{C}$ & 7 & 0.115 & W & 8 & 0.096 \\
\hline $\mathrm{Si}$ & 8 & 0.091 & $\mathrm{Si}$ & 6 & 0.081 & $\mathrm{Si}$ & 11 & 0.134 \\
\hline verage & & 0.098 & verage & & 0.091 & verage & & 0.104 \\
\hline
\end{tabular}
and atomic size difference factor $\lambda^{\prime}$ for ternary alloys of $\mathrm{Fe}-\mathrm{Y}_{10}-\mathrm{B}_{X}, \mathrm{Fe}-\mathrm{Y}_{10}-\mathrm{P}_{X}$ and $\mathrm{Co}-\mathrm{Y}_{10}-\mathrm{B}_{X} / 34 /$. 


\subsection{Compositional effect of solutes on the liquid structure with two model structures}

When the second element of $\mathrm{X}$ is added into metallic solvent of $\mathrm{M}$, the formation of new SRO denoted by $\mathrm{SRO}_{2}$ is likely in liquid alloys and this produces a distorted atomic distribution including $\mathrm{X}$ at a microscopic level mainly due to the atomic size difference in both metal-metalloid and metal-metal combinations. Such variation contributes to stabilizing the liquid phase disorder in the atomic distribution. When increasing the concentration of $\mathrm{X}$ beyond the minimum solute concentration $\left(C_{\mathrm{X}}^{\mathrm{m}}\right)$, certain numbers of $\mathrm{SRO}_{2}$ co-exist with $\mathrm{SRO}_{0}$, so that sufficient stability is attained. Then, glass formation starts by satisfying the good harmony of DRP with some defects in liquid alloys. In the relatively dilute region, it is quite natural that the additive element is surrounded by host metallic elements. Such local ordering in liquid alloys corresponds to the image originally proposed by Polk $125 /$ and this may be classified into the "Bernal type" $/ 38$ /, in which this type of glass can be characterized mainly by the DRP structure of the constituent elements with a certain amount of vacancy-like defects fully stabilized. This condition restrains the structure of liquid alloys from initiating nucleation and growth processes due to some competitive correlation with more than two kinds of SROs. The addition of the third element $(\mathrm{Y})$ into liquid alloys containing $X$ is known to enhance drastically both the stability and the ease of glass formation. However, when the basic feature of the atomic scale structure can be described by the DRP structure of the constituent elements, we may allow the glass to be called the "Bernal type".

Another type of structure should be considered when the formation of a stable cluster (SC) or middle range order (MRO) is clearly detected and such new ordering plays a rather important role in describing the basic structural features of liquid alloys. Alloys with a well defined local ordering presumably caused by strong chemical bonding between the host metal and solute elements are cases in point. For example, the formation of particular local ordering unit structure by harmonious coupling between more than two kinds of SROs is certainly suggested from the $X$-ray scattering results of the $\mathrm{Fe}_{70}-\mathrm{Y}_{10}-\mathrm{B}_{20}$ alloys (see Fig. 6). This type of liquid structure may be classified as "Chemical Order type" $138 /$, and corresponds to the "stereochemically defined model" proposed by Gaskell $/ 27 /$. One of the hallmarks of the Chemical Order type is the description of the essential structural features using the well defined local orderings. Relatively higher concentration of the solute elements is usually required to form sufficient numbers of such local ordering units.

The concept of these two typical model structures is also one way to describe a simple image of liquid or glassy alloys for differentiating one from another with a few essential structural features at a microscopic level. The tendency towards chemical order should also exist in the dilute region of the solute elements. However, such nature is not self evident. Conversely, the Bernal type features also remains in concentrated liquid alloys exhibiting SC or MRO, but such feature is constrained. The following comments from the thermodynamic point of view are qualitative but helpful for our understanding the GFA of liquid alloys.

Let us consider the excess Gibbs energy of the crystal embryo in the liquid state. The excess Gibbs energy of the crystal embryo, $\Delta G^{\text {ce }}$, is defined by the relation of $\Delta G^{\mathrm{ce}}=G^{\mathrm{ce}}-G_{l}$ with respect to a reference state of liquid $G_{l}$. On the other hand, the excess Gibbs energy of the non-crystalline SRO, $\Delta G^{\mathrm{SRO}}$, is similarly described by $\Delta G^{\mathrm{SRO}}=G^{\mathrm{SRO}}-G_{l}$. Both $\Delta G^{\mathrm{ce}}$ and $\Delta G^{\mathrm{SRO}}$ have contributions from both the volume and the surface of the crystal embryo or the non-crystalline SRO. The volume term is considered more negative with the degree of super-cooling $\Delta T$, and the surface term is positive at temperature below the melting point or crystallization temperature. The values of $\Delta G^{\text {ce }}$ and $\Delta G^{\mathrm{SRO}}$ increase initially with the number of atoms in the embryo $\left(N^{\text {ce }}\right)$ or SRO $\left(N^{\mathrm{SRO}}\right)$, reach a maximum at a critical size and then decrease, as in homogeneous nucleation. The size factor may be expressed by the sphere radius of crystal embryo or the non-crystalline SRO. For convenience of discussion, the relative positions of $\Delta G^{\mathrm{ce}}$ and $\Delta G^{\mathrm{SRO}}$ as a function of $N^{\mathrm{ce}}$ or $N^{\mathrm{SRO}}$ are illustrated in Fig. 10.

As shown in Fig. 10(a), $\Delta G^{\mathrm{SRO}}$ is greater than $\Delta G^{\text {ce }}$ in for all values of $N$ at temperatures below the melting point. In this condition, the crystal embryo will nucleate and grow and glass formation is not possible. By adding the second element $\mathrm{X}$ into host metallic solvent of $\mathrm{M}$, 
more than two SROs are formed in the liquid state and its disorder can be stabilized so as to form DRP distribution including $M$ and $X$. The minimum concentration of $\mathrm{X}$ required for glass formation is reached the height of the energy barrier is approximately equal for both the crystal embryo and the correlated SROs as described in Fig.10(b). With increasing concentration of $\mathrm{X}$ beyond this condition, the correlated SROs have lower energy and this hinders atomic redistribution for the growth of crystal embryo. Then, glass formation becomes to be favored.
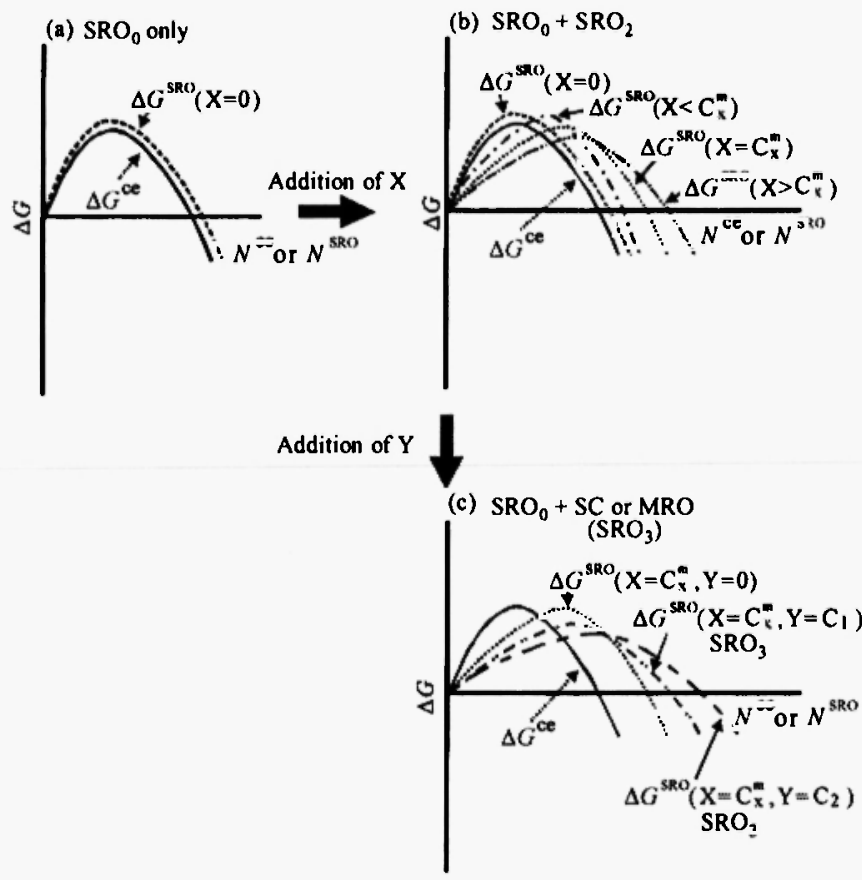

Fig. 10: The relative relationships (schematic diagram) for the excess free energies of the crystal embryo, $\Delta G^{\text {ce }}$, and non-crystalline SRO, $\Delta G^{\mathrm{SRO}}$, in liquid with respect to a reference state of liquid. (a) non-glass forming alloys, (b) alloys with $\mathrm{X}_{2}$ showing GFA ( $\mathrm{SRO}_{0}$ and $\mathrm{SRO}_{2}$ are included) and (c) alloys with $\mathrm{X}_{2}$ and $\mathrm{X}_{3}$ showing good GFA (SC or MRO are included)

By adding the third element $Y$ into the binary M-X liquid alloy, the formation of stable SRO which is referred to as SC or MRO is quite favored by harmonious coupling of the different SROs around the third element $(\mathrm{Y})$. This further lowers $\Delta G^{\mathrm{SRO}}$ as shown in Fig. 10(c), where the probability of formation of the relatively large size and stable SROs considerably exceeds the crystal embryo case for normal crystallization. This condition readily enhances the ease of glass formation. It may also be worth mentioning that the larger sphere radius of non-crystalline SRO, the wider the temperature span $\Delta T_{\mathrm{X}}$ (difference between the crystallization and glass transition temperatures) becomes.

Two model structures, denoted by the Bernal type and the Chemical Order type proposed by the present authors (YW and HSC /38/), may be one way to give a generalized novel description for the glass structure including the compositional effect of solutes on the structure of liquid alloys. Energetics of the completion between crystal embryo and different types of SRO is also helpful for our understanding the GFA of liquid alloys.

\section{THERMAL PROPERTIES OF BULK METALLIC GLASSES IN THE LIQUID STATE}

Thermal properties, such as thermal diffusivity or thermal conductivity, of bulk metallic glasses in the liquid state are considered of importance to estimate a temperature profile in a mold or to examine the relationship between thermal properties and the critical cooling rate for obtaining the glass phase. However, the available information is very limited because of experimental difficulties at high temperatures. Recently, some systematic results of thermal properties of Pdbased and $\mathrm{Zr}$-based liquid alloys were obtained $/ 39,40 /$. The salient points are given below.

The thermal diffusivity of six liquid alloy compositions are plotted in Fig. 11 as a function of normalized temperature, $\left(T-\mathrm{T}_{1}\right) / \mathrm{T}_{1}$, where $\mathrm{T}_{l}$ is the liquidus temperature. The thermal diffusivity at the liquidus temperature were estimated by extrapolation. The thermal diffusivity at the liquidus is plotted against the critical cooling rate of each alloy in Fig. 12. It is interesting that the lower the thermal diffusivity values of Pd-based alloys at liquidus temperature, the lower is the critical cooling rate needed to obtain a glass phase. 
The $\mathrm{Pd}_{40} \mathrm{Cu}_{30} \mathrm{Ni}_{10} \mathrm{P}_{20}$ alloy shows the highest GFA among three $\mathrm{Pd}$-based alloys presently investigated. The same trend is observed with the $\mathrm{Zr}$-based alloys. The best GFA is also found in the $\mathrm{Zr}_{55} \mathrm{Al}_{10} \mathrm{Ni}_{5} \mathrm{Cu}_{30}$ alloy among three $\mathrm{Zr}$-based alloys. The number of free electron in metallic liquid is quite likely decrease by forming SC or MRO whose character may be represented more or less by the covalent bonding. This is consistent with the low thermal diffusivity values of liquid alloys showing good GFA. The present results suggest that the thermal diffusivity values of alloys in the liquid state may be a good indicator of their GFA.

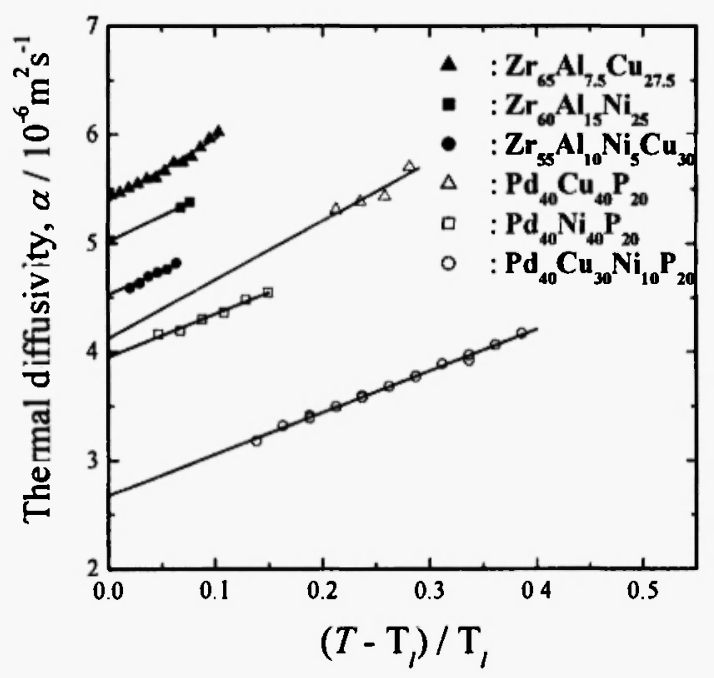

Fig. 11: Thermal diffusivity for Pd-based and $\mathrm{Zr}$ based liquid alloys as a function of $\left(T-\mathrm{T}_{l}\right) / \mathrm{T}_{l}, \mathrm{~T}_{l}$ is the liquidus temperature $139,40 \%$.

\section{CONCLUDING REMARKS}

The glass forming ability (GFA) of liquid alloys has been described by the concept of the short range order (SRO) definitely found in the nearest neighbor region. This includes the effects of solute elements (X and $Y$ ) on the liquid structure of metallic solvent (M) using four main factors. Particularly, the addition of the third element $(Y)$ into the liquid structure of $M$ containing $X$ contributes to stabilize the DRP structure due to the formation of stable cluster (SC) or middle range ordering (MRO) by harmonious coupling of different types of SROs. Nucleation and growth process is also restrained by increasing the energy requirement for atomic re-distribution. However, it is rather stated that the difference between SRO characterizing the liquid structure and near neighbor environment in the equilibrium crystalline phases is one of the important factors for GFA.

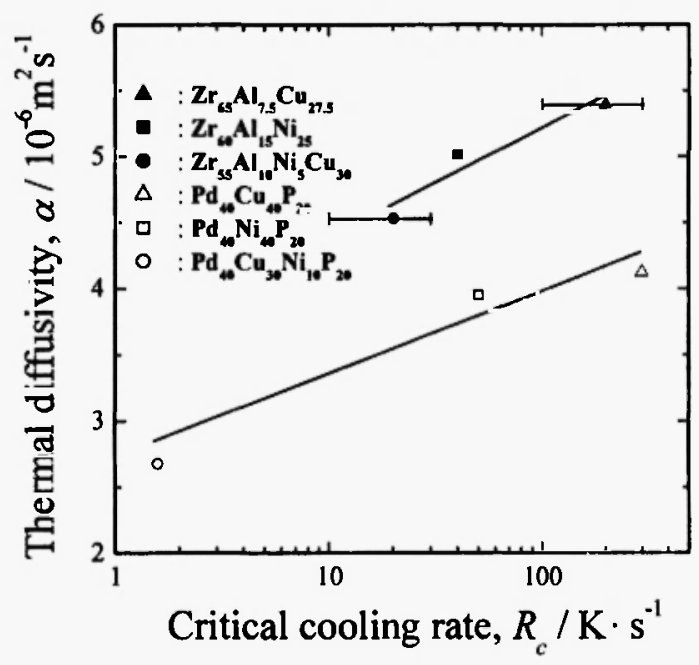

Fig. 12: Relationship between the thermal diffusivity values at liquidus temperature and the critical cooling rate for glass formation $\left(R_{c}\right)$ for Pdbased and $\mathrm{Zr}$-based liquid alloys $/ 39,40 /$.

The concept of two model structures denoted by the Bernal type and the Chemical Order type is qualitative but it has been found again to give a generalized novel description for the glass structure as a function of solute concentration. Current systematic experimental data on thermal diffusivities of Pd-based and $\mathrm{Zr}$-based liquid alloys clearly indicate that the thermal diffusivity may be a good indicator for GFA of liquid alloys.

\section{ACKNOWLEDGEMNTS}

The authors would like to express gratitude to Professors E. Matsubara, Y. Hirotsu, and A.P. Tsai for valuable discussions and comments. A part of this work was supported by the Grant-in-Aid for Scientific 
Research Fund from the Japan Society for Promotion of Science (No. 18029007 and 17206075).

\section{REFERENCES}

1. H.S. Chen and D. Turnbull, J. Chem. Phys. 48, 2560 (1968); Appl. Phys. Lett.,10 284 (1967); Acta Metall. 18, 261(1970).

2. H.S. Chen and K.A. Jackson: in Chapter 3 of Metallic Glasses, American Society for Metals, Metals Park, Ohio, 1978; p.74.

3. A. Inoue, T. Zhang and T. Masumoto: Mater. Trans. JIM, 31, 177 (1990).

4. T. Zhang, A. Inoue and T. Masumoto: Mater. Trans JIM, 32, 1005 (1991).

5. A. Peker and W.L. Johnson: Appl. Phys. Lett., 63, 2342 (1993).

6. A. Inoue: Bulk Amorphous Alloys, Preparation and Fundamental Characteristics, Trans. Tech. Pub., Zurich, 1998.

7. A. Inoue: Acta Mater. 48,279(2000).

8. N. Nishiyama and A. Inoue: Mater. Trans. JIM, 37, 1531 (1996).

9. A. Inoue: Japanese Scientific Monthly, 58, 584 (2005).

10. A. Inoue: Mater. Trans. JIM, 36, 866 (1995).

11. A. Inoue, T. Zhang and T. Masumoto: J. NonCryst. Solids, 156/158, 473 (1993).

12. A. Inoue: Kinzoku, 58, 7 (2005). Functions \& Materials, 22, 43 (2002).

13. T.G. Nieh and C.T. Lin: Proc. of $4^{\text {th }}$ International Conf. on Bulk Metallic Glasses, Gatlinburg, TN, USA, Intermetallics, 14, 855 (2006).

14. E. Matsubara, T. Tamura, Y. Waseda, A. Inoue, $T$. Zhang and T. Masumoto: Mater. Trans. JIM, 33, 873 (1992).

15. S. Ohkawa: Crystal Growth, Shokabou, Tokyo 1977.

16. G. Tamman: Zeit. Metallkde., 25, 236 (1933).

17. V.K. La Mer: Industrial and Engineering Chemistry, 44, 1270 (1952).

18. A.C. Zettlemoyer (Editor): Nucleation, Marcel Dekker, New York, 1969.

19. Y. Waseda: The Structure of Non-Crystalline Materials, McGraw-Hill, New York 1980.
20. J.M. Ziman: Adv. Phys., 13, 89 (1964).

21. N.W. Ashcroft and J Lekner: Phys. Rev., 145, 83 (1966).

22. N.W. Ashcroft and D.C. Langreth: Phys. Rev., 159, 500 (1967).

23. J.D. Bernal: Nature, 183, 141 (1959); Proc. Roy. Soc. London, A280, 299 (1964).

24. J.L. Finny: Proc. Roy. Soc. London, A319, 478 (1970).

25. D.E. Polk: Scripta Metall., 4, 117 (1970): Acta Metall. 20, 485 (1972).

26. M.R. Hoare: J. Non-Cryst. Solids, 31, 157 (1978).

27. P.H.Gaskell: $J$. Non-Cryst. Solids, 32, 207 (1979): Glassy. Metals II, edited by H. Beck and H.-J. Guntherodt, Springer, Heidelberg, 1983; p.5.

28. C.Y. Park,, M. Saito, Y. Waseda, N. Nishiyama and A. Inoue: Mater. Trans. JIM, 40, 491 (1999).

29. Y. Waseda: Anomalous X-ray Scattering for Materials Characterization, Springer, Heidelberg, 2002.

30. E. Matsubara, S. Sato, M. Imafuku, T. Nakamura, H. Koshiba, A. Inoue and Y. Waseda: Mater. Sci. Eng., A312, 136 (2001)

31. Y. Anderson: Acta Chem. Scand. Ser. A, 31A, 254 (1977).

32. E. Matsubara, S. Sato, M. Imafuku, T. Nakamura, H. Koshiba, A. Inoue and Y. Waseda: Mater. Res. Soc. Symp. Proc. 644, LI.1.1 (2001).

33. T. Egami and Y. Waseda: J.Non-Cryst. Solids, 64, 112 (1984).

34. S. Ueno and Y. Waseda: J. Mater. Eng., 9, 199 (1987).

35. H. Komoro: Thesis of Master of Eng., Tohoku University, 1984.

36. R. Bohmer and C.A. Angell: Phys. Rev., B45, 10091 (1992)

37. I.W. Donald and H.A. Davies: J. Non-Cryst. Solids, 30, 77 (1978).

38. Y. Waseda and H.S. Chen: Sci. Rep. Res. Inst. Tohoku Univ., A28, 143 (1980).

39. T. Nishi, H. Shibata, H. Ohta, N. Nishiyama, A. Inoue and Y. Waseda: Phys. Rev. B70, 174204 (2004).

40. H. Shibata, S. Nishihata, H. Ohta, S. Suzuki, Y. Waseda, M. Imafuku, J. Saida and A. Inoue: Mater. Trans., 48, 886 (2007). 